УДК 376

\title{
РАЗВИТИЕ СВЯЗНОЙ РУССКОЙ РЕЧИ У ДЕТЕЙ-БИЛИНГВОВ В НАЧАЛЬНОЙ ШКОЛЕ С ИСПОЛЬЗОВАНИЕМ ИГРОВОЙ ТЕХНОЛОГИИ (ПРИ РЕАЛИЗАЦИИ ФГОС НОО)
}

\section{Костеева Ольга Николаевна Скрыпник Галина Сергеевна} преподаватели высшей кв. категории МБОУ Дубковская СОШ «Дружба»

\begin{abstract}
Аннотация: Данная статья затрагивает в сфере образования проблему развития связной устной речи детей-билингвов. В статье представлена методика развития связной русской речи с использованием метода дидактической игры, который можно использовать как на уроках русского языка и литературного чтения, так и во внеурочной деятельности; а также представлена технологическая карта внеклассного занятия по русскому языку для 2 класса.
\end{abstract}

Ключевые слова: Билингвы, методика, дидактическая игра, устная речь.

\section{DEVELOPMENT OF COHERENT RUSSIAN SPEECH IN BILINGUAL CHILDREN IN PRIMARY SCHOOL USING GAME TECHNOLOGY (IN THE IMPLEMENTATION OF THE FEDERAL STATE EDUCATIONAL STANDARD)}

\section{Kosteneva Olga Nikolaevna Skrypnik Galina Sergeevna}

\begin{abstract}
This article touches upon the problems of the development of coherent oral speech of bilingual children in the field of education. Russian Russian language development methodology using the method of didactic play, which can be used both in Russian language lessons and literary reading, and in extracurricular activities, is presented in the article; as well as a technological map of extracurricular Russian language classes for the 2 nd grade.
\end{abstract}


Key words: Bilinguals, methodology, didactic game, oral speech.

Работая в нашей школе «Дружба» каждый год наблюдаем достаточно большое количество детей-первоклассников, которые приехали вместе с родителями из ближнего зарубежья. Проведя тестирование первоклассников в начале сентября, мы ежегодно выявляем тот факт, что такие дети зачастую имеют очень низкий уровень владения русским языком. Дети не посещали детский сад, семья общается только на родном языке, поэтому словарный запас детей-билингвов крайне беден.

При рождении человек не знает никакого языка. Но, вместе с тем, с рождения его окружают люди, говорящие на одном или нескольких языках. Слушая их, он начинает понимать и различать слова, строит на их основе свое мышление и в сознательном возрасте считает эти языки родными. Детей, которые сразу начинают говорить на двух языках, называют билингвами. Билингвы - это те, кто вырос в двуязычной системе. Когда ребенок в семье слушает один язык, а вне дома - другой (например, в бывших союзных республиках). Билингвизм в переводе с латыни означает «двуязычный». Следовательно, билингвизм - это способность говорить на двух языках. При этом необязательно, чтобы человек владел двумя языками на одном уровне. И это, кстати, довольно редкое явление, почти всегда один из языков является доминирующим.

Работая в начальной школе, мы начинаем общение с детьми-билингвами еще в первом классе. И сразу обращаем внимание на типичные ошибки в их устной речи:

- обращение к взрослым, в том числе, учителю, на «ты»;

- непонимание значений метафор, их скрытого смысла, например: ужасно красиво, холодные глаза, плачет небо;

- неразличение рода: «ты забыла свою портфель»;

- ошибки в употреблении глаголов: «я поставил на стол тетрадь»;

- ошибки в использовании падежных окончаний в словосочетаниях: «у меня нет книга», «он зовут».

Подобные обстоятельства создают значительные трудности в нашей работе при обучении двуязычных детей не только русскому языку, но и всем другим предметам. Современные учебные программы и учебники рассчитаны на русскоязычных детей. Зачастую, двуязычный ребенок не может понять содержание текста, и, в случае непонимания текста или заданий, родители не 
могут ему помочь, потому что, как правило, они знают русский язык даже хуже, чем их дети.

Проанализировав все вышесказанное, мы пришли к выводу, что начинать обучение двуязычных детей русскому языку как иностранному необходимо с помощью специальных дидактических игр. Высокий результат любого метода обучения зависит от учителя. Полноценное обучение возможно, если педагог хорошо знает не только методику обучения русскому языку в целом (особенно на начальном этапе), но и технику обучающей игры, и ее естественное развитие в обучении.

При выборе игровых технологий необходимо придерживаться следующих рекомендаций:

1. Когда преподаватель готовит игру, он должен четко сформулировать для себя две цели. Первая - это скрытая обучающая цель. Она сформулирована и реализована последовательно, но не доводится до сведения обучающихся. Вторая цель - игровая, которая ставится перед учениками и объясняется, как они могут ее достичь.

2. Перед игрой можно предложить ученикам образцы нужных словоформ, проговорить их хором.

3. Задача учителя - увлечь детей, заинтересовать более пассивных учеников.

4. Если учитель включает игру в урок, лучше всего провести ее во второй половине урока на этапе рефлексии, а так же полезно будет использовать ее при проведении физминутки.

5. Игра должна быть логически связана с материалом урока, с его темой.

\section{Игры с использованием различных предметов и подвижные игры.}

Перебрасывание мяча. Цель: отработка произношения на заданную тему. Один из игроков, бросая мяч своему напарнику, просит перечислить известные ему названия овощей (фруктов, мебели и т. д.), приметы осени и т. д.

Продолжи предложение. Цель: развитие навыков построения и использования сложных предложений. Ведущий (сначала учитель, а затем ученик) предлагает простое предложение. Задача каждого последующего игрока - продолжить это предложение, дополнить его второстепенными членами. Проиграет тот, кто не сможет продолжить предложение. 
Один лишний. Цель: отработать навыки проговаривания и запоминания синонимов, антонимов. Стулья ставят в круг (на один меньше участников) и играющие начинают ходить возле него. Сесть нужно по знаку ведущего. Учитель говорит: «Я называю слова-синонимы. Если среди них будет НЕ синоним, садитесь». Или: «Я называю слова одной группы - мебель, если среди них будет НЕ предмет мебели, садитесь». Тот, кто вовремя не успел сесть, выбывает из игры.

Игра с мячом. Цель: закрепление речевых выражений, употребление прилагательных в словосочетаниях. Дети встают в круг. Один играющий называет существительное (например, птица) и бросает мяч в руки другому. Тот, поймав мяч, должен назвать к существительному «птица» соответствующее прилагательное, правильно сочетая его по форме и окончанию.

Шифровалыщики. Цель: развитие и обогащение словарного запаса. Учитель пишет первую и последнюю букву слова, например у - - - - к. Задача играющего - узнать слово, подбирая буквы. Ведущий вписывает эту букву вместо черточки. Игра продолжается до тех пор, пока не дети разгадают слово.

Кто больше? Цель: повторение новых слов, закрепление их значений. Задание: назовите 10 слов, обозначающих учебную мебель. Назовите 10 слов, связанных с уроком математики, с дикими животными. Эту игру можно так же провести, используя мяч.

Угадай профессию. Цель: активизация глагольной лексики различных тематических групп. Ведущий называет профессию и ученик должен перечислить действия, связанные с этой профессией. Вопрос: «Что делает продавец?» (Принимает товар, продает, работает кассиром и т.д.)

В процессе проведения специальных дидактических игр знания, полученные на уроках, углубляются, у детей-билингвов возрастает интерес к языку, и, как следствие, к изучению различных учебных предметов. Каждый ребенок, даже плохо успевающий, имеет возможность активно заниматься интересным ему занятием, выбирать посильные задачи и расширять свой кругозор. Это - важный фактор для формирования познавательной активности, положительной мотивации к обучению, повышения самооценки, преодоления излишней застенчивости. 
В своей работе с детьми-билингвами мы используем дидактические игры на занятиях внеурочной деятельности «Путь к грамоте». Предлагаем конспект такого занятия (табл.1)

Таблица 1

Технологическая карта внеурочного занятия с детьми-билингвами «Путь к грамоте», 2 класс

\begin{tabular}{|c|c|c|c|}
\hline $\begin{array}{l}\text { Этапы } \\
\text { урока }\end{array}$ & Деятельность учителя & $\begin{array}{l}\text { Деятельность } \\
\text { учащихся }\end{array}$ & $\begin{array}{l}\text { Универсальные } \\
\text { учебные действия }\end{array}$ \\
\hline $\begin{array}{l}1 . \text { Само- } \\
\text { определе- } \\
\text { ние к } \\
\text { коррекцион } \\
\text { ной } \\
\text { деятельно- } \\
\text { сти }\end{array}$ & $\begin{array}{l}\text { - Здравствуйте. Начинаем } \\
\text { наше занятие. Давайте } \\
\text { вспомним, о чем мы с } \\
\text { вами говорим, что делаем } \\
\text { и чему учимся на наших } \\
\text { занятиях. }\end{array}$ & $\begin{array}{l}\text { - Учимся грамотно и } \\
\text { правильно, говорить на } \\
\text { русском языке, строим } \\
\text { правильно предложения, } \\
\text { учимся писать без } \\
\text { ошибок, закрепляем } \\
\text { правила русского языка, } \\
\text { которые изучили. }\end{array}$ & $\begin{array}{l}\text { Личностные: } \\
\text { самоопределение } \\
\text { Регулятивные: } \\
\text { целеполагание } \\
\text { Коммуникативные: } \\
\text { планирование учебного } \\
\text { сотрудничества с } \\
\text { учителем и сверстниками. }\end{array}$ \\
\hline $\begin{array}{l}\text { 2.Актуали- } \\
\text { зация и } \\
\text { пробные } \\
\text { учебные } \\
\text { действия }\end{array}$ & $\begin{array}{l}\text { - Какой ваш язык } \\
\text { является родным? } \\
\text { - Мой родной язык - } \\
\text { русский. Я работаю в } \\
\text { школе, где учатся много } \\
\text { детей разных } \\
\text { национальностей. } \\
\text { - Если бы все дети } \\
\text { говорили на своем } \\
\text { родном языке, смогли бы } \\
\text { мы понять друг друга? } \\
\text { - Поэтому нам нужно } \\
\text { учиться грамотно } \\
\text { разговаривать на русском } \\
\text { языке, чтобы общаться и } \\
\text { играть. Русский язык - } \\
\text { государственный язык в } \\
\text { России. } \\
\text { - А что значит - } \\
\text { государственный? } \\
\text { - Государственный - это } \\
\text { значит официальный язык } \\
\text { государства, самый } \\
\text { главный, все законы и все } \\
\text { общение происходит на } \\
\text { этом языке. }\end{array}$ & $\begin{array}{l}\text { - Ответы детей. } \\
\text { - Нет. } \\
\text { - Ответы детей. }\end{array}$ & $\begin{array}{l}\text { Коммуникативные: } \\
\text { планирование учебного } \\
\text { сотрудничества с } \\
\text { учителем и сверстниками; } \\
\text { Познавательные: } \\
\text { самостоятельное } \\
\text { выделение и } \\
\text { формулирование } \\
\text { познавательной цели. } \\
\text { Логические - } \\
\text { формулирование } \\
\text { проблемы. }\end{array}$ \\
\hline
\end{tabular}




\begin{tabular}{|c|c|c|c|}
\hline $\begin{array}{l}\text { 3.Формули } \\
\text { рование } \\
\text { проблемы }\end{array}$ & $\begin{array}{l}\text { Работа с карточкой №1. } \\
\text { - А сейчас мы с вами } \\
\text { поиграем в игру } \\
\text { «Расшифруй слово». } \\
\text { - Рассмотрите данные } \\
\text { слова. На каком языке они } \\
\text { написаны? - Как вы } \\
\text { думаете, какое будет } \\
\text { задание? } \\
\text { КАБАСО - } \\
\text { РОКОВА - } \\
\text { ВЕДЬМЕД - } \\
\text { АКСОРО- } \\
\text { ШАДЬЛО - } \\
\text { - Что объединяет эти } \\
\text { слова? } \\
\text { - Какое лишнее? } \\
\text { - Почему? } \\
\text { - Как вы думаете, о ком } \\
\text { пойдет речь на занятии? }\end{array}$ & $\begin{array}{l}\text { - Непонятно, на каком } \\
\text { языке. } \\
\text { - Составить правильные } \\
\text { слова на русском языке. } \\
\text { - СОБАКА } \\
\text { - КОРОВА } \\
\text { - МЕДВЕДЬ } \\
\text { - СОРОКА } \\
\text { - ЛОШАДЬ } \\
\text { - Это название животных. } \\
\text { - Сорока. } \\
\text { - Это птица. } \\
\text { - О птице сорока. }\end{array}$ & $\begin{array}{l}\text { Регулятивные: } \\
\text { целеполагание, } \\
\text { прогнозирование; } \\
\text { Познавательные: выбор } \\
\text { наиболее эффективных } \\
\text { способов решения задач в } \\
\text { зависимости от } \\
\text { конкретных условий }\end{array}$ \\
\hline $\begin{array}{l}\text { 4.Этап } \\
\text { построения } \\
\text { проекта. }\end{array}$ & $\begin{array}{l}\text { - Сегодня мы с вами } \\
\text { будем исследователями. } \\
\text { А кто это? } \\
\text { - У нас на занятии есть } \\
\text { шкатулка - она пока } \\
\text { пустая. Вы догадались, } \\
\text { что мы туда будем } \\
\text { складывать? } \\
\text { - Что вы уже знаете о } \\
\text { птице сорока? } \\
\text {-Как на вашем родном } \\
\text { языке будет слово } \\
\text { «сорока»? }\end{array}$ & $\begin{array}{l}\text { - Это люди, которые } \\
\text { исследуют и находят что- } \\
\text { то новое. } \\
\text { - Будем класть наши } \\
\text { исследования. } \\
\text { - Ответы детей. }\end{array}$ & $\begin{array}{l}\text { Предметные: } \\
\text { формирование навыков } \\
\text { построения моделей и } \\
\text { решения практических } \\
\text { задач. } \\
\text { Коммуникативные: } \\
\text { планирование учебного } \\
\text { сотрудничества с учителем } \\
\text { и сверстниками. } \\
\text { Познавательные: } \\
\text { моделирование, решение } \\
\text { проблемы, построение } \\
\text { логических цепей, анализ, } \\
\text { умение структурировать } \\
\text { знания }\end{array}$ \\
\hline $\begin{array}{l}\text { 5.Этап } \\
\text { реализации } \\
\text { построенно } \\
\text { го проекта. } \\
\text { Исследова- } \\
\text { ние слова. }\end{array}$ & $\begin{array}{l}\text { Работа со словарем. } \\
\text { - Давайте найдем в } \\
\text { толковом словаре значение } \\
\text { слова «сорока». } \\
\text { - СОРОКА - крупная } \\
\text { длиннохвостая птица из } \\
\text { семейства вороновых. } \\
\text { (Шкатулка наполняется - } \\
\text { мы узнали точное } \\
\text { определение). } \\
\text { - А кто знает, почему } \\
\text { сороку сорокой зовут? } \\
\text { Просмотр короткого } \\
\text { учебного фильма про } \\
\text { сороку, происхождение } \\
\text { слова. } \\
\text { - Что вы запомнили о } \\
\text { происхождении слова? } \\
\text { (Шкатулка наполняется - } \\
\text { уточнили точное } \\
\text { определение слова). }\end{array}$ & $\begin{array}{l}\text { - Свое имя сорока } \\
\text { получила от слова } \\
\text { «сорка», передающее } \\
\text { особенности ее пения. }\end{array}$ & $\begin{array}{l}\text { Регулятивные: } \\
\text { контроль и коррекция; } \\
\text { прогнозирование } \\
\text { Коммуникативные: } \\
\text { учебное сотрудничество с } \\
\text { учителем и сверстниками } \\
\text { Познавательные: } \\
\text { логические (установление } \\
\text { причинно-следственных } \\
\text { связей, построение } \\
\text { логической цепи } \\
\text { рассуждений }\end{array}$ \\
\hline
\end{tabular}




\begin{tabular}{|c|c|c|c|}
\hline $\begin{array}{l}\text { 6.Физ- } \\
\text { минутка }\end{array}$ & \multicolumn{2}{|c|}{$\begin{array}{l}\text { ФИЗМИНУТКА - ИГРА «Верни мяч!» } \\
\text { Один играющий называет существительное на тему } \\
\text { «Птицы» и бросает мяч в руки другому игроку. } \\
\text { Поймав мяч, ребенок возвращает его, добавив } \\
\text { соответствующее прилагательное. }\end{array}$} & \\
\hline $\begin{array}{l}7 . \text { Обобще- } \\
\text { ние } \\
\text { затрудне- } \\
\text { ний во } \\
\text { внешней } \\
\text { речи }\end{array}$ & $\begin{array}{l}\text { Составление } \\
\text { предложений (карточка } \\
\text { №2). } \\
\text { - Перед вами разложены } \\
\text { слова. } \\
\text { - Какое задание вам надо } \\
\text { выполнить? } \\
\text { - Сорока сидит на ... } \\
\text { - Она питается ... } \\
\text { - Сорока любит } \\
\text { блестящие .... } \\
\text { - Сорока каждый год } \\
\text { строит новое ... }\end{array}$ & $\begin{array}{l}\text { - Составить предложения. } \\
\text { - ветке. } \\
\text { - насекомыми, грызунами, } \\
\text { птенцами. } \\
\text { - вещи. } \\
\text { - гнездо. }\end{array}$ & $\begin{array}{l}\text { Регулятивные: } \\
\text { определение } \\
\text { последовательных, } \\
\text { промежуточных целей с } \\
\text { учетом конечного } \\
\text { результата. } \\
\text { Коммуникативные: } \\
\text { умение с достаточной } \\
\text { полнотой и точностью } \\
\text { выражать свои мысли }\end{array}$ \\
\hline $\begin{array}{l}8 . \text { Груп- } \\
\text { повая } \\
\text { работа с } \\
\text { самопрове- } \\
\text { ркой по } \\
\text { эталону }\end{array}$ & $\begin{array}{l}\text { Дети садятся в группы по } \\
\text { трое. } \\
\text {-У вас готовы } \\
\text { предложения. } \\
\text {-Что будем делать дальше? } \\
\text { Составление коротких } \\
\text { рассказов, с опорой на } \\
\text { предложение. } \\
\text { Проверка рассказов, } \\
\text { самооценка. } \\
\text { - Прочтите части текста. } \\
\text { Что необходимо сделать? } \\
\text {-Чего не хватает? } \\
\text {-Что нужно сделать? }\end{array}$ & $\begin{array}{l} \\
\text {-Соединить все части в } \\
\text { один рассказ. } \\
\text {-Названия. } \\
\text {-Придумать название. }\end{array}$ & $\begin{array}{l}\text { Регулятивные: } \\
\text { саморегуляция как } \\
\text { способность к } \\
\text { мобилизации сил и } \\
\text { энергии к волевому } \\
\text { усилию и преодолению } \\
\text { препятствий } \\
\text { Познавательные: } \\
\text { формулирование } \\
\text { проблемы, создание } \\
\text { способов решения } \\
\text { проблемы, } \\
\text { исследовательская } \\
\text { деятельность }\end{array}$ \\
\hline $\begin{array}{l}9 . \text { Включе- } \\
\text { ние в } \\
\text { систему } \\
\text { знаний и } \\
\text { повторения. }\end{array}$ & $\begin{array}{l}\text { Работа с текстом. } \\
\text { Прочтите все части текста. } \\
\text { Ответьте на вопросы: } \\
\text {-Где обычно обитает } \\
\text { сорока? } \\
\text { - Чем питается сорока? } \\
\text { - Как разводит потомство? } \\
\text { - Что любит? Почему? } \\
\text { Шкатулка наполняется - } \\
\text { готов рассказ про сороку. } \\
\text { Работа с фразеологизмами. } \\
\text {-Какие крылатые } \\
\text { выражения вы знаете про } \\
\text { сороку? } \\
\text { - Соедините устойчивое } \\
\text { выражение речи с его } \\
\text { значением. } \\
\text { - Сорока... } \\
\text { - Трещит как... } \\
\text { - Сорока... } \\
\text { - Объясните значение этих } \\
\text { выражений. }\end{array}$ & $\begin{array}{l}\text { - на хвосте принесла. } \\
\text { - сорока } \\
\text { - воровка. } \\
\text { - Ответы детей. }\end{array}$ & $\begin{array}{l}\text { Регулятивные: } \\
\text { целеполагание } \\
\text { (постановка учебно- } \\
\text { познавательной задачи на } \\
\text { основе соотнесения того, } \\
\text { что уже известно и } \\
\text { усвоено и того, что } \\
\text { неизвестно. } \\
\text { Познавательные: } \\
\text { оценка процесса } \\
\text { результата деятельности. }\end{array}$ \\
\hline
\end{tabular}




\begin{tabular}{|c|c|c|c|}
\hline $\begin{array}{l}\text { 10.Рефлек- } \\
\text { сия } \\
\text { учебной } \\
\text { деятельно- } \\
\text { сти на } \\
\text { занятии }\end{array}$ & $\begin{array}{l}\text { - Вы сегодня работали на } \\
\text { занятии и в группе, и все } \\
\text { вместе, и каждый } \\
\text { отдельно. Кого бы вам } \\
\text { хотелось отметить? } \\
\text {-Перед вами - рисунок со } \\
\text { шкатулкой. Оцените сам } \\
\text { себя - если нравится, как } \\
\text { работал, раскрасьте вашу } \\
\text { шкатулку полностью, } \\
\text { если работали вполсилы - } \\
\text { наполовину, если } \\
\text { работали неважно- совсем } \\
\text { чуть-чуть. } \\
\text { - А посмотрите на нашу } \\
\text { шкатулку. Почему она } \\
\text { наполнена не вся? } \\
\text {-Значит, дома почитайте } \\
\text { книги, сказки, статьи про } \\
\text { жизнь сороки. }\end{array}$ & $\begin{array}{l}\text { Оценивают собственную } \\
\text { деятельность, намечают } \\
\text { цели последующей } \\
\text { деятельности. В } \\
\text { соответствие с } \\
\text { результатами } \\
\text { деятельности } \\
\text { согласовывают дом } \\
\text { задание. } \\
\\
\\
\text { - О сороке мы узнали еще } \\
\text { не все. }\end{array}$ & $\begin{array}{l}\text { Коммуникативные: } \\
\text { умение с достаточной } \\
\text { полнотой и точностью } \\
\text { выражать свои мысли; } \\
\text { Регулятивные: } \\
\text { планирование, контроль, } \\
\text { оценка, коррекция, } \\
\text { выделение и осознание } \\
\text { того, что усвоено, что } \\
\text { ещё подлежит усвоению }\end{array}$ \\
\hline
\end{tabular}

В заключение хочется сказать: обучение детей-билингвов - сложная и серьезная проблема. Формы обучения второму языку должны быть направлены не только на усвоение как можно большего количества лексических единиц, но и на стимулирование интереса к русскому языку, а также на развитие у ребенка коммуникативных навыков, умения самовыражаться. Важно добиться хорошего качества усвоения материала, которое позволит ребенку осмысленно и по ситуации использовать слова и речевые обороты русского языка.

(C) О.Н. Костеева, Г.С. Скрыпник, 2021 